\title{
SUBJETIVIDADE INDÍGENA NO BLOG GASODÁ SURUÍ
}

\section{LUCIMAR LUISA FERREIRA}

\author{
Faculdade Nossa Senhora Aparecida \\ Av. Pedro Luiz Ribeiro, Qd. 01, Lt. 01, Chácara Santo Antônio - Gleba 04 A \\ Conjunto Bela Morada - 74920-760 - Aparecida de Goiânia - GO - Brasil \\ lucimarluisa@uol.com.br
}

\begin{abstract}
Resumo. Os estudos sobre blogs são inúmeros, entretanto, na grande maioria, os enfoques giram em torno dos aspectos técnicos, funcionais ou pragmáticos. Essas abordagens, centradas nas noções de comunicação e de interação, pressupõem um sujeito intencional, mestre do sentido, o usuário do computador. Deslocando a noção de usuário para a de sujeito discursivo, o objetivo deste estudo é compreender a constituição do sujeito indígena no processo de formulação em um blog pessoal, tendo em vista os gestos de interpretação e os deslocamentos de sentidos na rede mundial de computadores. O enfoque teórico do trabalho é a Análise de Discurso e o corpus é formado por materiais diversos (página inicial, perfil e post) recortados do blog Gasodá Suruí.
\end{abstract}

Palavras-chave: blog; usuário; sujeito indígena; imaginário .

\begin{abstract}
Studies on blogs abound, however, in most cases, the approaches revolve around the technical, functional or pragmatic aspects. These approaches, centered on communication and interaction concepts, assume an intentional subject, the sense master, the computer user. Moving the user notion to the discursive subject, the aim of this study is to understand the constitution of indigenous subject in the formulation process on a personal blog, in view of the interpretation gestures and shifts of meaning in the world wide web. The theoretical work focus is the Discourse Analysis and the corpus is made up of various materials (homepage, profile and post) cut from the blog Gasodá Suruí.
\end{abstract}

Keywords: blog; user; indigenous subject; imaginary .

\section{Introdução}

Em grande parte das discussões contemporâneas sobre internet, mídias digitais, rede eletrônica, a noção de usuário funciona como base. Essas abordagens, que fazem parte de uma concepção comunicativa e pragmática da linguagem, pressupõem um sujeito consciente e intencional, o usuário do computador. Mas, se considerarmos o funcionamento do discurso no processo de formulação em um $b \log$, o sujeito não é o euconsciência, que age, interage e realiza atos através da linguagem. Além disso, as relações de significação não são dadas e nem naturais.

Numa perspectiva discursiva, o sujeito se constitui imaginariamente em uma posição, interpelado pela ideologia e inscrito numa rede de sentidos. Isso porque a relação 
entre mundo e linguagem só acontece por intermédio da ideologia ${ }^{1}$. É através da ideologia, pela ideia de prática e de mediação, que se pode tratar da incompletude e da falha na linguagem (ORLANDI, 2007). E, com as noções de incompletude e de falha na linguagem, torna-se possível a compreensão do funcionamento da interpretação e/ou dos deslocamentos de sentidos. De acordo com Orlandi (2007, p. 30), "diante de qualquer objeto simbólico ' $x$ ' somos instados a interpretar o que ' $x$ ' quer dizer", pois há para $o$ sujeito uma injunção à interpretação e esta se dá porque o espaço simbólico é marcado pela incompletude, pela relação com o silêncio e com o interdiscurso.

Para Dias (2004), é fato que o cálculo é a base da linguagem dos programas informáticos, porém, sobretudo com a telemática, o computador passa a ser um lugar para a constituição do sujeito e do sentido na articulação da língua com a história, em que entram o imaginário e a ideologia. Com essa compreensão, a prática de textualização em um blog pode ser compreendida como parte de um complexo jogo imaginário, no que diz respeito à imagem que o sujeito blogueiro tem de si mesmo, do objeto do discurso e dos seus interlocutores online, o efeito-leitor.

Para tratar da constituição do sujeito indígena na formulação no blog Gasodá Suruí, buscamos deslocar a noção genérica de usuário da internet para a de sujeito discursivo. No caso que analisamos, o blogueiro indígena não é apenas um usuário do computador que publiciza assuntos pessoais e intimidades na rede/internet. $\mathrm{O}$ indígena se constitui sujeito autor no blog, posição a partir da qual formula e interpreta, podendo, com esse gesto, deslocar sentidos na rede mundial de computadores.

\section{Condições de produção e formulação em blogs}

De acordo com Pecheux (1997), há uma relação necessária entre as "circunstâncias" de um discurso e os mecanismos formais que o produzem. Nesse sentido, o funcionamento de uma formulação não pode ser descrito como integralmente linguístico, pois é necessário referi-lo ao "mecanismo de colocação dos protagonistas e do objeto do discurso", isto é, considerar as condições de produção em sentido estrito e amplo. Para Orlandi (1999), as condições de produção, por sua vez, compreendem os sujeitos, a situação e a memória. As condições podem ser compreendidas em sentido estrito (as circunstâncias da enunciação, o contexto imediato) e, em sentido amplo (o contexto sócio-histórico e ideológico).

Em um blog, as condições de produção em sentido estrito são formadas pelo contexto da enunciação online e, em sentido amplo, pelo contexto sócio-histórico e ideológico da formulação e interlocução mediada por computador, ou seja, elementos que derivam da forma como a nossa sociedade organiza o poder. Assim, as condições de produção no blog Gasodá Suruí podem ser representadas pela formulação de um indígena que assume a função-autor e se dirige a um público leitor, na ilusão de interatividade, tendo em vista a memória discursiva e a memória metálica.

\footnotetext{
${ }^{1}$ Conforme Orlandi (1999), a ideologia é aquilo que define a direção dos efeitos de sentido.
} 
A memória discursiva é o saber que torna possível todo dizer e que retorna sob a forma do pré-construído, o já-dito que está na base do dizível, sustentando cada tomada da palavra. $\mathrm{O}$ interdiscurso disponibiliza dizeres que afetam o modo como o sujeito significa em uma situação discursiva dada (ORLANDI, 1999). Já a memória metálica, conforme Orlandi (2010), é a memória da máquina, da circulação, que não se produz pela historicidade, mas por um construto técnico.

Para Gallo (2011, p. 418), nas textualizações próprias da internet, "uma quase indistinção entre o que é discurso da escrita e o que é discurso da oralidade é produzida, sendo que o instantâneo pode ser o definitivo". Nesse tipo de discurso, que Gallo (2011) denomina de discurso da escritoralidade, as fronteiras entre o oral e o escrito são diluídas e uma nova forma de autoria pode se constituir em um processo no qual o sujeito se torna autor de seu texto de forma instantânea, fora das instituídas instâncias de legitimação do dizer. Nesses processos discursivos permanentemente em curso, os sujeitos são autores sustentados por uma memória metálica, ou seja, a memória produzida pelo arranjo.

Partindo dessa noção de escritoralidade, consideramos que os blogs podem representar bem essa nova maneira de formular da internet, uma formulação específica, que funciona sob o efeito de uma autoria constituída nessas novas condições de produção. No processo de composição, configuração e produção dos posts em um blog, o sujeito assume a função-autor e a partir dessa função produz gestos de interpretação, sustentado pela memória e interpelado pela ideologia.

Para Orlandi (2007), a função-autor se realiza toda vez que o produtor da linguagem se representa na origem dos sentidos, produzindo um texto com unidade, coerência, progressão, não contradição e fim. Em outras palavras, ela se aplica ao corriqueiro da fabricação da unidade do dizer comum, afetada pela responsabilidade social. No blog, o indígena assume a função-autor, a partir da qual interpreta, se responsabilizando pelo que faz circular na rede/internet. Para compreender a constituição do sujeito indígena autor e o funcionamento dos seus gestos de interpretação no processo de formulação no blog, é necessário considerar as condições de produção em sentido estrito e em sentido amplo.

\section{O sujeito discursivo: imaginário e interpretação}

Conforme Mariani (2003, p. 61), “o sujeito, para a Análise do Discurso, é uma posição material linguístico-histórica produzida em meio ao jogo, contradições e tensões sócio-ideólogicas". Essas posições-sujeito correspondem às projeções imaginárias dos lugares sociais que estão representados nos processos discursivos em que são colocados em jogo. Isso quer dizer que as posições-sujeito são constituídas a partir do funcionamento das formações imaginárias, que sustentam o jogo de antecipações de sentidos no processo de interlocução.

Pelo mecanismo de antecipação, o sujeito antecipa-se a seu interlocutor quanto ao sentido de suas palavras. Para Orlandi (1999), esse mecanismo regula a argumentação 
de tal forma que o sujeito dirá de um modo, ou de outro, segundo o efeito que pensa produzir em seu interlocutor. De acordo com Baldini (2011) o imaginário está presente em todas as relações, sejam elas virtuais ou não. As relações chamadas 'virtuais' não escapam ao 'jogo da memória', já que todo dizer, na realidade, se encontra na confluência dos dois eixos: o da memória (constituição) e o da atualidade (formulação).

Considerando o funcionamento do imaginário na formulação em um blog, o mecanismo pode ser compreendido através do funcionamento da interlocução online, a qual pressupõe uma posição-autor na relação com o efeito-leitor. Em um blog, o blogueiro assume a função-autor e a partir dessa função cria, compõe (em termos de layout e de design da página) formata e produz os posts, considerando sempre a relação com o interlocutor imaginário.

Com efeito, podemos dizer que a posição-autor se faz na relação com a constituição de um lugar de interpretação definido pela relação com o Outro (o interdiscurso) e o outro (interlocutor). O que, em análise de discurso, está subsumido pelo chamado efeito-leitor. Assim se configura a determinação ideológica da autoria. (ORLANDI, 2007, p. 74)

Todo esse processo acontece sob o efeito ideológico de o sujeito ser a origem do sentido, tendo em vista que ao optar por um ou outro elemento de design, de forma de layout da página e tipo de publicação, o sujeito o faz a partir de uma interpretação, de uma posição e de um processo de filiação discursiva. Ou seja, no processo de composição visual e formato da página, da configuração ou da produção dos posts, o sujeito interpreta filiado a uma rede de sentidos determinados historicamente, tendo sempre em vista o efeito-leitor.

Partindo desses fundamentos, é necessário considerar que o blogueiro indígena, na formulação, criação e na manutenção do seu blog, o faz a partir de um processo imaginário de antecipação de sentidos. E, de acordo com Orlandi (1999), o imaginário não brota do nada: assenta-se no modo como as relações sociais inscrevem na história e são regidas em uma sociedade, como a nossa, por relações de poder. Nesse caso em análise, o blogueiro indígena, num imaginário de interlocução direta e sem intermediários, se coloca na origem do sentido, com a possibilidade de levar conhecimentos sobre os indígenas ao leitor, que busca informações.

O blog, nesse caso, aparece significado como um espaço de dizer que possibilita a circulação dos gestos de interpretação indígenas, historicamente silenciados nas mídias convencionais: rádio, jornal e tevê. E esse processo pode significar redefinição nas relações de poder no que diz respeito à circulação de sentidos dos/sobre os indígenas interditados ao longo da história.

\section{Gestos de interpretação no blog Gasodá Suruí}

Pensando que um dizer elege um sentido na cadeia parafrástica e que essa seleção é resultado da intervenção da ideologia, no Blog Gasodá Suruí, o blogueiro formula os 
textos, argumentando numa direção contrária aos sentidos e estereótipos ${ }^{2}$ sobre os indígenas que circulam no imaginário social, tendo em vista o já-dito, o pré-construído do discurso ocidental ${ }^{3}$. Nesse processo, são os gestos de interpretação do sujeito indígena no blog que podem possibilitar o deslocamento de sentidos na rede/internet.

Para Orlandi (2004), o gesto de interpretação é um ato ao nível simbólico. Com o objetivo de discutir o funcionamento dos gestos de interpretação indígenas, desenvolvo uma análise de alguns elementos do blog Gasodá Suruí: página inicial, perfil e posts. Gasodá Suruí é um blog pessoal, criado em abril de 2009 e, embora trate de diferentes assuntos relacionados às ações e à cultura do povo Suruí, se destaca na postagem de matérias relacionadas à vida passoal do autor. Esse blog, em uma classificação genérica, poderia ser considerado diário ${ }^{4}$, mas se analisado numa perspectiva discursiva, é possível compreender que ele não é apenas um diário.

Embora trate, na maior parte das matérias, de assuntos ligados à vida pessoal e formação do autor, no discurso, o que se constrói é a imagem positiva de um sujeito indígena que tem formação acadêmica, exerce funções, conhece direitos e usa a tecnologia. Nesse caso específico em análise, por mais que o sujeito poste assuntos pessoais, a direção argumentativa de seu discurso aponta para a reformulação da imagem indígena estereotipada que circula na mídia.

Podemos observar esse funcionamento na página inicial, no perfil e em um post do blog Gasodá Suruí, do ano de 2011, figura 1, abaixo.

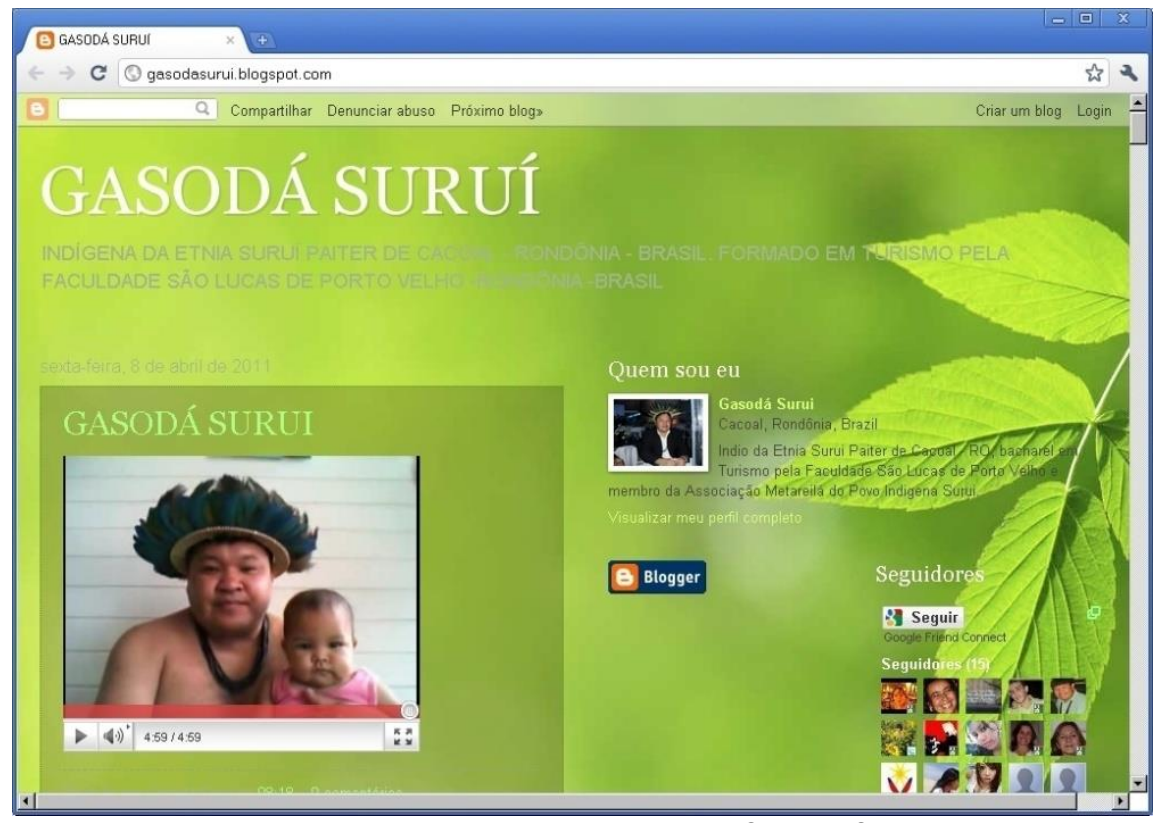

Figura 1: Página inicial do blog Gasodá Suruí, em 2011.

\footnotetext{
2 A palavra "estereótipo" é usada conforme a definição de Azambuja (2005).

${ }^{3}$ Cf. Orlandi, 1990.

${ }^{4}$ Cf. Marcuschi (2010), Komesu (2010) e Schittine (2004).
} 
Na página inicial do $b \log ^{5}$ aparece um fundo verde, tendo como título destacado, o nome do autor. O blogueiro não usa pseudônimo e posta uma foto sua no perfil. Nesse blog, o nome e a foto em destaque, mostra que o blogueiro não pretende se manter no anonimato. Pelo contrário, através do nome e da foto, o sujeito indígena se coloca em evidência no blog. O nome dá destaque para o sujeito, mas também para o povo, já que o nome indígena é composto pelo nome da etnia. Nesse funcionamento, o sujeito não é apenas uma individualidade, mas sim, parte de uma coletividade, de um grupo, de uma etnia, de um povo, o Suruí Paiter.

Mas outros elementos da formulação dão a especificidade de significação desse sujeito indígena. Na fotografia do perfil, o blogueiro aparece vestido de terno com um cocar na cabeça. A fotografia, através do formato e do enquadramento, materializa sentidos de documento, de cadastro e, indiretamente, de trabalho. $\mathrm{O}$ sujeito (o blogueiro indígena), embora vestido de terno, traz na cabeça um cocar. E, através desse elemento, que não é apenas um adorno, o blogueiro se significa no lugar da diferença étnica. $O$ terno é um elemento que significa a formalidade da posição do sujeito autor e o cocar materializa a especificidade desse sujeito, que é um indígena.

Nesse caso, o cocar pode significar, via discurso transverso, a especificidade da cultura indígena, mantida em funcionamento na identificação do sujeito na posição de autor no blog. Para Pêcheux (1995, p. 166) “o funcionamento do 'discurso transverso' remete àquilo que, classicamente, é designado por metonímia, enquanto relação da parte com o todo, da causa com o efeito, do sintoma com o que ele designa etc." O cocar é a materialidade que significa, nesse caso, a diferença étnica Suruí, significativa na identificação do sujeito.

No blog Gasodá Suruí, o sujeito indígena assume a função-autor na rede mundial de computadores, destacando a sua condição de ser indígena. Esse sentido é reafirmado na descrição do texto do perfil. Nessa descrição, o sujeito se denomina indígena brasileiro. Veja o texto reproduzido na sequência discursiva, Sd 1, a seguir:

\begin{abstract}
Sd 1 - Gosodá Suruí
Cacoal, Rondônia, Brazil

Indigena Brasileiro Pertencente ao Povo Paiter de Rondônia. Graduado em Turismo pela Faculdade São Lucas de Porto Velho - Brasil. Atualmente e Coordenador de Cultura Gamebey e responsavel pelo Projeto de Elaboração de Plano de Turimo Paiter na Associação Metareilá do Povo Indigena Surui ${ }^{6}$.
\end{abstract}

Nesse texto, o sujeito se denomina indígena brasileiro, dando relevo à condição de ser indígena. O sujeito é um indígena brasileiro de uma etnia específica, Suruí Paiter. Ao se apresentar como índio da etnia Suruí Paiter, de Cacoal-RO, o sujeito se mostra parte de um povo indígena, que reside em um estado brasileiro, Rondônia. O sujeito é antes de tudo um indígena, que vive em uma área (terra) indígena, em uma região do país.

O blogueiro se autodenomina indígena brasileiro, formado em turismo e membro de uma Associação do Povo Indígena Suruí. E ser brasileiro, nessas circunstâncias,

\footnotetext{
${ }^{5}$ Disponível em http://gasodasurui.blogspot.com/; acesso em maio 2011.

${ }^{6}$ Blog Gasodá Suruí. Disponível em http://gasodasurui.blogspot.com/; acesso em maio 2011.
} 
funciona sob o efeito de sentido de cidadania, ou seja, um sujeito que tem deveres e direitos garantidos na Constituição Federal do Brasil. Nesse caso, o sujeito autor do blog se significa como individualidade, sujeito de direito, perante o Estado, inscrito no discurso jurídico ${ }^{7}$, mas ao mesmo tempo como parte de uma coletividade, de uma etnia, atravessado pelo discurso indígena suruí. A qualificação, nesse funcionamento discursivo, é apresentada como argumento da possibilidade de um indígena adquirir conhecimentos de outras culturas sem perder a sua. $\mathrm{O}$ argumento da formação e da ocupação do blogueiro formula uma imagem positiva de um indígena que adquiriu elementos da cultura ocidental, mas que mantém a sua cultura significativa e em funcionamento.

Nesse gesto de interpretação, o indígena não é significado como "menos evoluído" por manter a especificidade de sua cultura, ou melhor, a sua "evolução" não lhe tira a condição de ser índio. $O$ argumento que sustenta essa interpretação é o de que o sujeito continua sendo índio, por mais que tenha formação, exerça funções, saiba escrever na língua portuguesa e domine a nova tecnologia, a ferramenta $b l o g$.

No post, em um vídeo, o blogueiro fala de si e apresenta a sua filha, um bebê de colo. Nesse vídeo, o sujeito aparece sem camisa, de cocar na cabeça e colar indígena. Pensando a formulação, há um deslizamento da formalidade da posição de autor do blog para a informalidade de um indígena na sua vida cotidiana na aldeia. A informalidade da vida cotidiana na aldeia não é apenas a exposição da vida privada no espaço publico da rede. A informalidade aparece sustentando o discurso indígena de manutenção da cultura e da diferença étnica. O sujeito indígena se constitui em duas posições: o índio suruí autor do blog e o índio suruí pai de família, sustentado por um imaginário de que um sujeito indígena, assim como qualquer outro, pode ocupar várias posições na sociedade.

Nesse post, ao se expor no vídeo, falando de si e de sua vida pessoal, o sujeito produz um gesto de interpretação sobre si e sua família, expondo no espaço público aspectos de sua vida privada. Mas, nesse caso, falar da vida pessoal e apresentar a filha, embora seja uma maneira de apresentar as questões pessoais privadas no espaço público da rede, tem um funcionamento peculiar, pois essa apresentação faz parte da construção da uma imagem indígena diferente da que circula na mídia. Em termos de discurso, o sujeito promove um deslocamento de sentidos de índios como sujeito do passado ao se apresentar fisicamente no vídeo, falando oralmente sobre si e sua filha bebê. No discurso formulado no vídeo, os indígenas são sujeitos do presente e, com a apresentação da criança, produz um efeito de que também serão do futuro.

Pelo que é possível perceber, toda a interpretação do sujeito autor do blog funciona a partir de um processo de antecipação de sentidos, a partir do qual a formação acadêmica e as funções que desempenha, funcionam como afirmação da capacidade intelectual e competência técnica que um indígena pode ter. De acordo com Orlandi (1998, p. 76), todo sujeito experimenta o lugar do ouvinte a partir do seu próprio lugar, constituído pelo jogo das formações imaginárias. "Cada um 'sabe' prever onde seu ouvinte o espera. Esta antecipação do que o outro vai pensar é constitutiva de todo discurso". No discurso indígena no blog, a antecipação funciona em relação ao imaginário produzido pelo discurso ocidental, a partir do qual os indígenas são "povos do passado" "menos evoluídos" e se adquirem elementos de outras culturas deixam de ser o que são.

${ }^{7}$ Cf. Lagazzi, 1988. 
Essa forma de apresentação do autor do blog tem relação direta com o imaginário de um interlocutor interpelado pelo discurso ocidental, ou seja, o efeito-leitor construído pelo discurso indígena no blog é um leitor que desconhece os indígenas do país e os significa a partir de estereótipos, que circulam no imaginário social. É a partir desse efeito-leitor que o blogueiro posta um vídeo se apresentando e apresentando a sua filha.

Nesse processo, a materialidade linguística é a base em que se realizam simbolicamente as relações de forças e de sentidos que emergem dos confrontos ideológicos que atravessam a formação social. Assim, no processo de formular uma imagem positiva dos índios na rede/internet, a interpretação indígena no blog promove o deslocamento de sentidos para os quais ser índio é manter um cultura estática.

O post não é assinado, mas nesse tipo de postagem a assinatura não é necessária, já que o blog apresenta o mecanismo "Postado por" com o nome do autor na sequência. Esse funcionamento dá ao blogueiro o status de autor, colocando o sujeito na origem do dizer e responsável pelo que faz circular na rede. No blog, o sujeito produz seus gestos de interpretação, acreditando poder direcionar e conter os sentidos de seus posts, partindo do imaginário de um leitor não indígena conectado, que procura informações.

Para Romão (2006, p.17), na posição autor, o sujeito "precisa ter domínio (ainda que imaginariamente) dos sentidos que supõe produzir, fazendo movimentos de referenciação, antecipação e retroação, não deixando o sentido ir para qualquer lugar nem ser qualquer um". No blog analisado, a busca pela contenção dos sentidos pode ser observada no processo da escolha da cor verde para o fundo da página, no tipo de fotografia, no recorte de texto escrito no perfil, na imagem que compõe a postagem, na entonação da fala que aparece no vídeo e todos os demais elementos verbais e não verbais que integra a formulação. Todos esses movimentos de direcionamento dos sentidos são efeitos do funcionamento da autoria, ou seja, o sujeito, no trabalho de fechamento e construção da unidade do texto, assume a função-autor, a partir da qual se coloca imaginariamente na origem dos sentidos que supõe produzir.

Considerando que a linguagem é um sistema que adquire significado, inscrevendo-se na história (ORLANDI, 2002), na formulação, através das diferentes materialidades, uma imagem indígena positiva e atual é colocada em circulação, numa relação de deslocamento de sentidos, a partir dos quais os indígenas são significados negativamente. Em termos de discurso, esse fato pode ser compreendido como um gesto de interpretação do sujeito indígena nas condições de produção específicas do blog. Nesse sentido, o blog possibilita ao indígena se significar fora dos estereótipos do discurso ocidental, que circulam no imaginário social, reforçado pela mídia.

\section{Considerações finais}

A partir das discussões teóricas e análises realizadas neste trabalho, é possível compreender que o autor do blog analisado não é apenas um indígena usuário da internet que age, interage e publiciza suas intimidades na rede mundial de computadores. O blog também não é apenas um sistema de produção de diários online, como alguns estudos 
preconizam. O blogueiro indígena que escreve em seu blog, na ilusão da interatividade, produz os seus textos a partir de um processo de interpelação ideológica do indivíduo em sujeito e pela identificação deste com os sentidos de uma determinada formação discursiva. Nesse caso, o blogueiro, na criação e na manutenção do seu blog, o faz a partir de um imaginário que tem de si, do objeto do discurso e dos interlocutores online, numa posição de autor que assume.

O blogueiro indígena, numa posição de resistência aos sentidos do discurso ocidental, produz os seus gestos de interpretação e, nesses gestos, promove deslocamentos de sentidos na rede. No processo de composição da página inicial, da configuração e de produção dos posts, o sujeito, autor indígena, se significa na diferença étnica. E, dessa forma, a interpretação indígena produzida no blog, pode legitimar, fora das instâncias instituídas, gestos de interpretação indígenas silenciados ao longo da história.

Nesse caso, ao postar o seu texto na rede mundial de computadores, o autor do blog não apenas sofre os efeitos da memória metálica, a memória da circulação. $\mathrm{O}$ sujeito, na função-autor, mesmo que se submenta às condições da memória metálica, que, segundo Orlandi (2010) não historiciza, faz ecoar, via interdiscurso, uma especificidade indígena, um já-dito suruí. Isso acontece porque, mesmo que seja por intermédio da máquina, num espaço de memória metálica, se há um processo de linguagem, há sempre a falta, a falha e, nesse processo de incompletude, há possibilidade do novo, dos gestos de interpretação do sujeito. E é nesse sentido que o discurso da escrituralidade, no processo de produzir efeito de autoria sobre sujeitos não alinhados às conhecidas instância de legitimação do discurso da escrita, pode, via função-autor, dar eco ao discurso indígena na rede/internet.

No caso que analisamos, o indígena não é apenas um usuário da internet ou escrevente de posts que circulam na Web, ele é um sujeito, constituído no processo de formulação e interlocução, ocupando uma posição de autoria, constituída a partir das novas possibilidades de publicação própria do blog.

Tendo em vista que o espaço aberto pela rede/internet ultrapassa o sistema de uso, as práticas de linguagem produzidas em suporte digital são práticas de sujeitos constituídos pelo imaginário e interpelados pela ideologia, tendo em vista o caráter simbólico, histórico e político da linguagem, independente do seu suporte ou de sua materialidade. Sendo assim, para os indígenas, o blog pode ser considerado espaço de discurso que constitui o movimento da resistência, já que promove a circulação dos gestos de interpretação e dos deslocamentos de sentido na rede mundial de computadores.

\section{Referências Bibliográficas}

AZAMBUJA, Elizete Beatriz. Olhares, vozes e silêncios que excluem: estereótipo de índio. Cáceres: Editora Unemat, 2005. 
BALDINI, Lauro. J. S. Cidade e sujeito na rede. Em: ORLANDI, Eni. P. (Org.). Discurso, espaço, memória: caminhos da identidade no sul de Minas. Campinas, SP: Editora RG, 2011. pp. 57-68.

DIAS, Cristiane Pereira. A discursividade da rede (de sentidos): a sala de bate-papo hiv. Tese. Doutorado em Linguística. Instituto de Estudos da Linguagem, Universidade Estadual de Campinas, Campinas, SP, 2004.

GALLO, Solange Leda. Da escrita a escrituralidade: um percurso em direção ao autor online. Em: RODRIGUES, Eduardo Alves et al. (Orgs.). Análise de discurso no Brasil: pensando o impensado sempre. Campinas, SP: Editora RG, 2011. pp. 411- 423.

KOMESU, Fabiana Cristina. Blogs e as práticas de escrita de si na internet. Em: MARCUSCHI, Luiz Antônio; XAVIER, Antonio Carlos (Orgs.). Hipertexto e gêneros digitais: novas formas de construção de sentidos. $3^{\mathrm{a}}$. ed. São Paulo: Cortez, 2010. pp. 135-146.

LAGAZZI, Suzy. O desafio de dizer não. Campinas, SP: Pontes, 1988.

MARCUSCHI, Luiz Antônio; XAVIER, Antonio Carlos (Orgs.). Hipertexto e gêneros digitais: novas formas de construção de sentidos. $3^{\text {a }}$. ed. São Paulo: Cortez, 2010.

MARIANI, Bethania. Subjetividade e imaginário linguístico. Linguagem em (Dis)curso. Universidade do Sul de Santa Catarina. Tubarão, Unisul, v. 1, n.1, pp. 55- 72, 2003.

ORLANDI, Eni. O contrapelo: incursão teórica na tecnologia - discurso eletrônico, escola, cidade. RUA [on-line; Revista do Laboratório de Estudos Urbanos do Núcleo de Desenvolvimento da Criatividade], v. 2, n. 16, pp. 1-14, 2010. Disponível em http://www.labeurb.unicamp.br/rua/; acesso em jan. 2012.

Interpretação: autoria, leitura e efeito do trabalho simbólico. $5^{\mathrm{a}}$. ed. Campinas, SP: Pontes Editores, 2007.

Cidade dos sentidos. Campinas, SP: Pontes, 2004.

Língua e conhecimento linguístico: para uma história das ideias no Brasil. São Paulo: Cortez, 2002.

Análise de Discurso: princípios e procedimentos. Campinas, SP: Pontes, 1999.

(Org.). A leitura e os leitores. Campinas, SP: Pontes, 1998.

Terra à vista: discurso do confronto: velho e novo mundo. São Paulo: Cortez; Campinas: Editora da Unicamp, 1990.

PÊCHEUX, Michel. Semântica e discurso: uma crítica à afirmação do óbvio. Trad. Bras. $2^{\text {a }}$. ed. Campinas, SP: Editora da Unicamp, 1995. 
Análise de conteúdo e teoria do discurso. Em: GADET, Françoise; HAK, Tony. Por uma análise automática do discurso: uma introdução à obra de Michel Pêcheux. Trad. Bras. $3^{a}$. ed. Campinas, SP: Editora da Unicamp, 1997. pp. 61-105.

ROMÃO, Lucília M. S. O cavalete, a tela e o branco: introdução à autoria na rede eletrônica. DELTA. v. 22, n. 2, pp. 303-328, 2006.

SCHITTINE, Denise. Blog: comunicação e escrita íntima na internet. Rio de Janeiro: Civilização Brasileira, 2004.

\section{Para citar este texto:}

FERREIRA, Lucimar Luisa. Subjetividade indígena no blog Gasodá Suruí. Entremeios [Revista de Estudos do Discurso], Seção Estudos, Programa de Pós-graduação em Ciências da Linguagem (PPGCL), Universidade do Vale do Sapucaí, Pouso Alegre (MG), vol. 12, p. 81-91, jan. - jun. 2016.

DOI: http://dx.doi.org/10.20337/ISSN2179-3514revistaENTREMEIOSvol12pagina81a91 